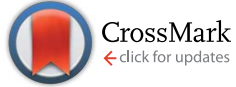

Cite this: Chem. Sci., 2014, 5, 4179

Received 12th June 2014

Accepted 9th July 2014

DOI: $10.1039 / \mathrm{c} 4 \mathrm{sc} 01746 \mathrm{c}$

www.rsc.org/chemicalscience

\title{
A solvent-resistant halogen bond $\uparrow$
}

\author{
Craig C. Robertson, ${ }^{a}$ Robin N. Perutz, ${ }^{\star b}$ Lee Brammer*a and Christopher A. Hunter ${ }^{\star a}$
}

The effect of solvent on the stabilities of complexes involving a single $\mathrm{H}$-bond or halogen-bond (X-bond) has been quantified. Association constants for binary complexes of 4-(phenylazo)phenol, molecular iodine, tetramethylurea and tetramethylthiourea have been measured in fifteen different solvents by UV/vis absorption and ${ }^{1} \mathrm{H}$ NMR titration experiments. The stabilities of the $\mathrm{H}$-bonded complexes decrease by more than three orders of magnitude with increasing solvent polarity. In contrast, the X-bonded complex of molecular iodine with tetramethylthiourea is remarkably insensitive to the nature of the solvent (association constants measured in alkanes and alcohols are similar). The results suggest that, in contrast to $\mathrm{H}$-bonds, where electrostatics determine thermodynamic stability, charge-transfer interactions make a major contribution to the stability of these $\mathrm{X}$-bonded complexes rendering them resistant to increases in solvent polarity.

\section{Introduction}

A halogen bond (X-bond) is an attractive interaction between an electron-deficient halogen and a Lewis base or $\pi$-system..$^{1-3} \mathrm{X}$ -

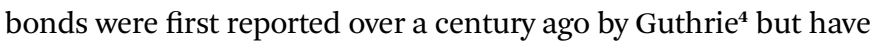
recently become a focus of attention in the fields of crystal engineering, ${ }^{5-10}$ protein-ligand interactions, ${ }^{11,12}$ catalysis ${ }^{13}$ and supramolecular and materials chemistry. ${ }^{\mathbf{1 4 - 2 0}}$ Analysis of the geometries of $\mathrm{X}$-bonds, $\mathrm{D}-\mathrm{X} \cdots \mathrm{A}$, in crystal structures reveal directional preferences that point to the role of the halogen " $\sigma$ hole" situated trans to the covalent D-X bond (DX and A are the Xbond donor and acceptor respectively). However, it is not clear whether this observation is due to the fact that (a) the $\sigma$-hole is the best site for an electrostatic interaction because the $\sigma$-hole is the most positive region on the molecular electrostatic potential surface, or (b) due to the fact that the $\sigma$-hole is the best site for a charge transfer interaction because the $\mathrm{D}-\mathrm{X} \sigma^{*}$ orbital is low in energy. ${ }^{21}$ Here we resolve this issue by investigating the effect of solvent on the thermodynamic stabilities of X-bonded complexes.

The thermodynamic properties of X-bonds have been characterized for a wide range of complexes in non-polar organic solvents. ${ }^{22-24}$ Laurence et al. used experimentally determined association constants for $1: 1$ complexes formed with molecular iodine in alkane solvents to develop a thermodynamic scale, $\mathrm{p} K_{\mathrm{BI} 2}$, to classify $\mathrm{X}$-bond acceptor functional groups. ${ }^{22 a}$ The $\mathrm{p} K_{\mathrm{B} 2}$ scale shows some parallels with the corresponding scale developed for $\mathrm{H}$-bond interactions, $\mathrm{p} K_{\mathrm{BHX}}$, which is based

${ }^{a}$ Department of Chemistry, University of Sheffield, Brook Hill, Sheffield, S3 7HF, United Kingdom.E-mail: c.hunter@shef.ac.uk

${ }^{b}$ Department of Chemistry, University of York, Heslington, York, YO10 5DD, United Kingdom

$\uparrow$ Electronic Supplementary Information (ESI) available: Titration methods and data. See DOI: $10.1039 / \mathrm{c} 4 \mathrm{sc01746c}$ on experimentally determined association constants for formation of $1: 1$ complexes with 4-fluorophenol in carbon tetrachloride. ${ }^{25}$ However, there are some clear differences between the two scales, which suggests that there are fundamental differences between the factors that govern the thermodynamic properties of X-bonds and $\mathrm{H}$-bonds. X-bonds are generally weaker than H-bonds, so experimental studies have focused on non-polar solvents, but here we show that it is possible to quantify X-bond interactions in much more polar solvent environments, providing some unique insight into the fundamental nature of the interaction.

Fig. 1 illustrates the electrostatic solvent competition model that we have developed for H-bonding interactions. ${ }^{26}$ The energy of a pairwise intermolecular interaction is estimated using the $\mathrm{H}$-bond parameters, $\alpha$ and $\beta$, and solution-phase free energy change for complexation is obtained by comparing stabilities of the four complexes in Fig. 1 (eqn (1)).

$$
\Delta G_{\mathrm{calc}}^{\circ}=-\left(\alpha-\alpha_{\mathrm{S}}\right) \times\left(\beta-\beta_{\mathrm{S}}\right)+c
$$

where $\alpha$ and $\beta$ are the $\mathrm{H}$-bond donor and acceptor parameters of the solutes, $\alpha_{\mathrm{S}}$ and $\beta_{\mathrm{S}}$ are the solvent $\mathrm{H}$-bond parameters, and

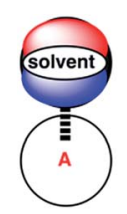

$\alpha_{\mathrm{S}} \beta$

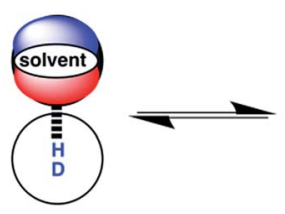

$\alpha \beta_{\mathrm{S}}$

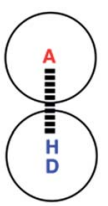

$\alpha \beta$

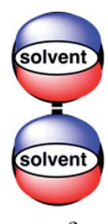

$\alpha_{\mathrm{S}} \beta_{\mathrm{S}}$
Fig. 1 Formation of a complex between a $\mathrm{H}$-bond donor $(\mathrm{D}-\mathrm{H})$ and a $\mathrm{H}$-bond acceptor (A). The position of equilibrium is determined by the four interaction energies, which can be estimated using the $\mathrm{H}$-bond parameters $\alpha, \beta, \alpha_{\mathrm{S}}$ and $\beta_{\mathrm{S}}$ (see eqn (1)). ${ }^{26}$ 


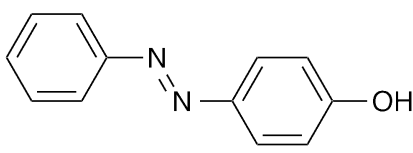<smiles>CN(C)C(=O)N(C)C</smiles>

3
2

$\mathrm{I}_{2}$

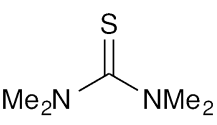

4
Scheme $1 \mathrm{H}$-bond donor 4-(phenylazo)phenol $1(\alpha=4.2), \mathrm{X}$-bond donor iodine 2 and acceptors 3 tetramethylurea $(\beta=8.8)$ and 4 tetramethylthiourea $(\beta=6.4){ }^{26}$

the constant $c$ was experimentally determined to be $6 \mathrm{~kJ} \mathrm{~mol}^{-1}$ in carbon tetrachloride solution and is assumed to be unchanged for other solvents.

The parameters used in eqn (1) can be derived from molecular electrostatic potential surfaces calculated for the isolated molecules in the gas phase, so the thermodynamic properties of $\mathrm{H}$-bonds can be estimated in a straightforward way from the chemical structures of the components. ${ }^{27}$ The validity of eqn (1) was confirmed by comparison of $\Delta G_{\text {calc }}^{\circ}$ with experimental measurements on a range of different complexes in different solvents. ${ }^{28}$ eqn (1) implies that the solvent competes for interactions at specific sites on the solutes and that the bulk solvent properties do not play an important role. Studies of solvent effects therefore offer excellent opportunities to probe the nature of intermolecular interactions, and here we apply this approach to X-bonds.

The compounds used are shown in Scheme 1. The $1 \cdot 3 \mathrm{H}$ bonded complex and the $\mathbf{2} \cdot \mathbf{4} \mathrm{X}$-bonded complex are both known to be very stable in non-polar solvents, ${ }^{26,29}$ so these systems are promising candidates for quantifying binding interactions in more competitive solvents. In addition, the interaction of molecular iodine with thiocarbonyl compounds has been extensively studied by a variety of spectroscopic methods, and characteristic signatures have been identified for the different covalent and non-covalent adducts that can be formed. ${ }^{30}$

\section{Results and discussion}

UV/vis absorption titrations were carried out on the two $\mathrm{H}$ bonded complexes, $\mathbf{1} \cdot \mathbf{3}$ and $\mathbf{1} \cdot \mathbf{4}$, and the two X-bonded complexes, $\mathbf{2} \cdot \mathbf{3}$ and $\mathbf{2} \cdot \mathbf{4}$, in fifteen different solvents. Typical results are illustrated in Fig. 2 (see ESI $\uparrow$ for full details). The $\pi-$ $\pi *$ absorption band of 1 shifts from $336-342 \mathrm{~nm}$ to $350-354 \mathrm{~nm}$ on formation of a H-bond (Fig. 2a). Fitting the titration data to a $1: 1$ binding isotherm gave the association constants recorded in Table 1. For some systems, absorption of the guest or the solvent obscured part of the UV/vis spectrum, so titrations were also carried out using ${ }^{1} \mathrm{H}$ NMR spectroscopy. For systems where both UV/vis and NMR titrations were carried out, the results were consistent. (a)

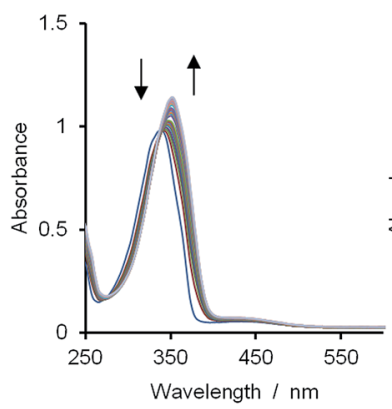

(b)

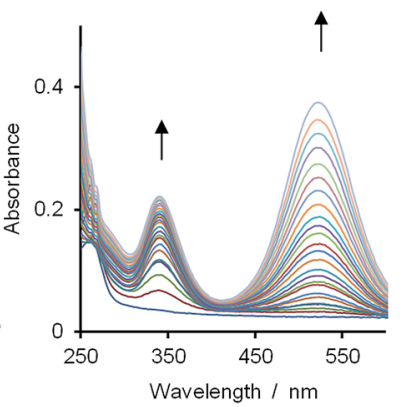

Fig. 2 UV/vis spectra for titrations of (a) 3 into a $0.1 \mathrm{mM}$ solution of 1 and (b) 2 into a $0.01 \mathrm{mM}$ solution of 4 in $n$-octane at $298 \mathrm{~K}$.

Table 1 Association constants $\left(\mathrm{M}^{-1}\right)$ measured by UV/vis or ${ }^{1} \mathrm{H}$ NMR titrations at $298 \mathrm{~K}^{a}$

\begin{tabular}{|c|c|c|c|c|}
\hline \multirow[b]{2}{*}{ Solvent } & \multicolumn{2}{|c|}{ H-bond } & \multicolumn{2}{|c|}{$\mathrm{X}$-bond } \\
\hline & $1 \cdot 3$ & $1 \cdot 4$ & $2 \cdot 3$ & $2 \cdot 4$ \\
\hline$n$-Octane & 2400 & 370 & 12 & 8800 \\
\hline Carbon tetrachloride & 410 & $24^{b}$ & 6 & 7300 \\
\hline Toluene & 230 & 4 & 3 & 11000 \\
\hline Diiodomethane & $210^{b}$ & $6^{b}$ & $<1$ & 37000 \\
\hline Dibromomethane & 110 & $<1$ & $<1$ & 34000 \\
\hline Dichloromethane & 90 & 9 & 2 & $58000^{b}$ \\
\hline Chloroform & 52 & $2^{b}$ & 1 & 20000 \\
\hline 1,1,2,2-Tetrachloroethane & 35 & $6^{b}$ & $<1$ & 55000 \\
\hline Di- $n$-octyl ether & $<1$ & $<1$ & $<1$ & 1600 \\
\hline Acetone & $2^{b}$ & $<1$ & $<1$ & $1900^{b}$ \\
\hline Acetonitrile & $3^{b}$ & $<1$ & $<1$ & $2800^{b}$ \\
\hline Nitromethane & $5^{b}$ & $<1$ & $<1$ & $2100^{b}$ \\
\hline$i$-Propanol & $<1$ & $<1$ & $<1$ & $3600^{b}$ \\
\hline Ethanol & $<1$ & $<1$ & $<1$ & $3200^{b}$ \\
\hline Methanol & $<1$ & $<1$ & $<1$ & $2700^{b}$ \\
\hline
\end{tabular}

${ }^{a}$ See ESI for errors. In all cases, greater than $50 \%$ saturation of the binding isotherm was achieved. ${ }^{b}$ Measured by ${ }^{1} \mathrm{H}$ NMR titration.

The $\mathbf{2} \cdot \mathbf{4}$ complex has a charge-transfer absorption band with $\lambda_{\text {max }}$ observed in the range $330-340 \mathrm{~nm}$, depending on solvent (Fig. 2b; ESI Section $8 \dagger$ ). In addition, the $\pi_{\mathrm{g}}-\sigma_{\mathrm{u}}$ absorption band of 2 shifts from $\lambda_{\max }$ in the range $478-523 \mathrm{~nm}$ to $431-450 \mathrm{~nm}$ on formation of a X-bond. The latter blue-shifted band is more difficult to discern in the titration of 2 into 4 (Fig. 2b), but clearly evident in the titration of 3 into 2 (Fig. S37†). Fig. 3 shows the spectra for the fully bound X-bonded complexes $2 \cdot 3$ and $2 \cdot \mathbf{4}^{31}$ The charge-transfer band at 330-340 $\mathrm{nm}$ dominates in the $\mathbf{2 \cdot 4}$ spectrum but is not present in the UV/vis spectrum of the $\mathbf{2 \cdot 3}$ complex. The blue-shifted band for 2 at $431-450 \mathrm{~nm}$ is now clearly evident for both complexes. Thiocarbonyl compounds can react with molecular iodine to form a variety of different covalent adducts. ${ }^{30}$ However, the charge-transfer band observed in the $\mathbf{2} \cdot \mathbf{4}$ titrations is characteristic of a complex where the I-I bond is intact. ${ }^{32}$ In polar solvents, the $\mathbf{2 \cdot 4}$ complex did react slowly to give new signals in the ${ }^{1} \mathrm{H}$ NMR spectrum (see $\operatorname{ESI} \dagger$ ). Formation of these covalent adducts did not occur over the timescale of the titration experiments reported here. 


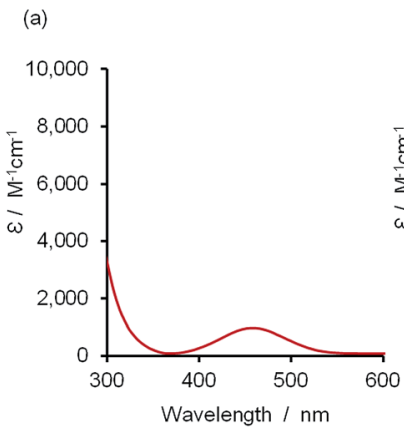

(b)

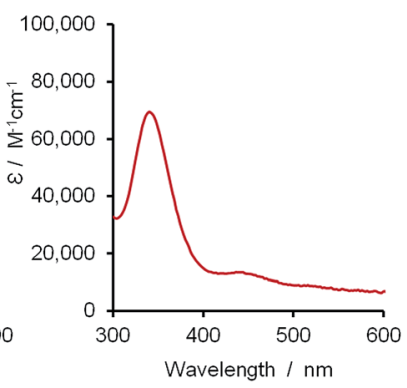

Fig. $3 \mathrm{UV} / \mathrm{vis}$ spectra of (a) the $2 \cdot 3$ complex and (b) the $2 \cdot 4$ complex calculated from the UV/vis titration data in $n$-octane. ${ }^{31}$

The association constants measured for the $\mathrm{H}$-bonded complexes, $\mathbf{1} \cdot \mathbf{3}$ and $\mathbf{1} \cdot \mathbf{4}$, span three orders of magnitude, and the values agree well with the free energy changes predicted by eqn (1) (Fig. 4, data in blue and red respectively). This implies that the stabilities of the complexes are determined simply by the relative polarities of the solutes and solvents: the complexes formed with 3 are more stable than the complexes formed with 4 in all solvents, because 3 is a more polar $\mathrm{H}$-bond acceptor; the complexes are most stable in the least polar solvent, $n$-octane, and the stability decreases with solvent polarity, so that binding is too weak to measure in the most polar solvent, methanol.

The $\mathbf{2} \cdot \mathbf{3}$ X-bonded complex is the least stable of all four complexes studied. This complex is most stable in the least polar solvent, $n$-octane, and the stability decreases with solvent polarity, so that binding is too weak to measure in most

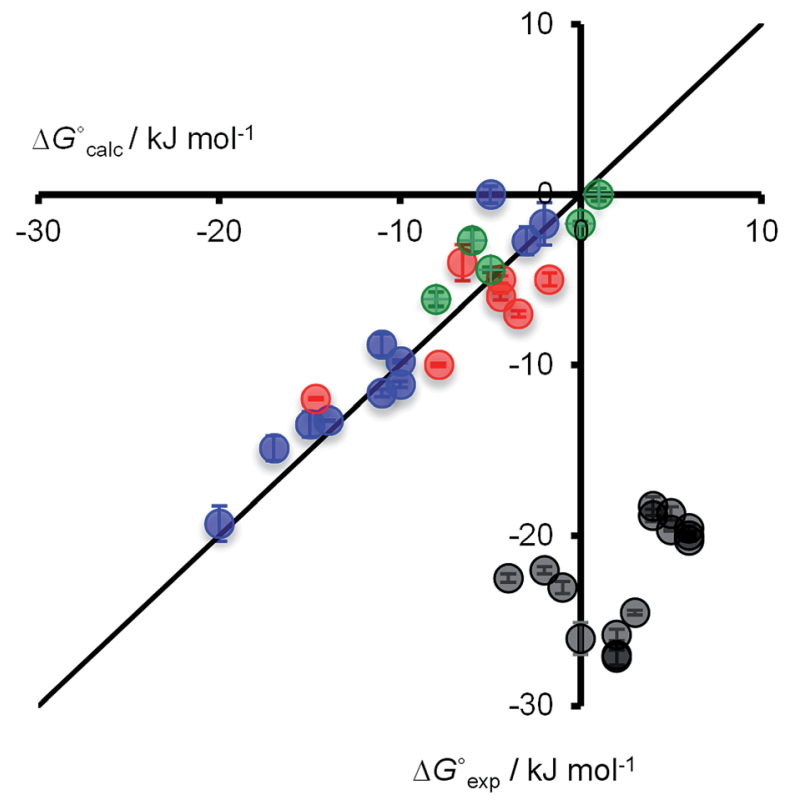

Fig. 4 Comparison of experimental free energy changes on complexation $\left(\Delta G_{\text {exp }}^{\circ}\right)$ with the values calculated using eqn (1) $\left(\Delta G_{\text {calc }}^{\circ}\right)$ for $\mathrm{H}$-bonded complexes ( 1.3 shown in blue and 1.4 in red) and $\mathrm{X}$ bonded complexes ( $2 \cdot 3$ shown in green and $2 \cdot 4$ in grey). Experimental errors at the $95 \%$ confidence limit. The line represents $\Delta G_{\text {calc }}^{\circ}=\Delta G_{\text {exp }}^{\circ}$. solvents. In contrast, the $\mathbf{2} \cdot \mathbf{4} \mathrm{X}$-bonded complex is the most stable of the four complexes studied, and association constants could be measured in all fifteen solvents. The stability of this complex shows a remarkably different solvent-dependence from the other three complexes. The $\mathbf{2 \cdot \mathbf { 4 }}$ association constant in the most polar solvent, methanol, decreases only 3 -fold compared with the value determined in the least polar solvent, $n$-octane. This result was confirmed by measuring the stability of the $\mathbf{2 \cdot 4}$ complex in different alcohols, ethanol and $i$-propanol, which gave very similar results to methanol.

The association constants for the $\mathbf{2} \cdot \mathbf{3} \mathrm{X}$-bonded complex show a similar solvent-dependence to the H-bonded complexes, which suggests that an effective value of $\alpha$ for molecular iodine can be estimated for 2 using eqn (1) (Fig. 4). A fit of the experimental data for the $2 \cdot 3$ complex to eqn (1) yields $\alpha=2.8$ (data in green). However, this value of $\alpha$ (or any other) fails to predict the properties of the $\mathbf{2} \cdot \mathbf{4}$ complex (Fig. 4, data in gray). The electrostatic solvent competition model illustrated in Fig. 1 is clearly not suitable for describing solvent effects on the stability of the $\mathbf{2} \cdot \mathbf{4}$ X-bonded complex.

An investigation of the interaction of solvent with 2 was carried out by measuring association constants for all $\mathbf{2} \cdot$ solvent complexes in $n$-octane. The association constants in all cases are small $\left(K_{\mathrm{a}} \leq 2 \pm 1 \mathrm{M}^{-1}\right.$, Table $\left.\mathrm{S} 2 \dagger\right)$ and showed no correlation with the stability of the $\mathbf{2} \cdot \mathbf{4}$ complex in these solvents. In addition, there is no correlation between the association constant for the $\mathbf{2} \cdot \mathbf{4}$ complex and bulk solvent properties (see Fig S78 $\dagger$ ). UV/vis absorption titrations carried out in mixtures of $n$-octane and 1,1,2,2-tetrachloroethane (TCE) show that $\Delta G_{\text {expt }}^{\circ}$ is a linear function of the concentration of TCE, and there is no evidence of preferential solvation of the $\mathbf{2} \cdot \mathbf{4}$ complex that would lead to stabilization of the complex in halogenated solvents (see Fig S77†).

The results in Table 1 and Fig. 4 indicate that the factors that govern the stability of the $\mathbf{2} \cdot \mathbf{4} \mathrm{X}$-bond are quite different from the other three complexes. For example, the association constants for the $\mathbf{1} \cdot \mathbf{4}, \mathbf{1} \cdot \mathbf{3}$ and $\mathbf{2} \cdot \mathbf{3}$ complexes are more than an order of magnitude lower in TCE than in $n$-octane, whereas the $\mathbf{2} \cdot \mathbf{4}$ complex is 6 times more stable in TCE than in $n$-octane. The UV/vis spectrum of the $\mathbf{2 \cdot 4}$ complex is also different from the other three complexes in that there is a strong charge-transfer absorption band. The wavelength (330-340 $\mathrm{nm}$ ) and extinction coefficient (30 000$55000 \mathrm{M}^{-1} \mathrm{~cm}^{-1}$ ) of this band are similar in all solvents where values could be measured (see ESI $\dagger$ ). Crystal structures of complexes between molecular iodine and thiocarbonyl compounds exhibit geometries with short $\mathrm{S} \cdots \mathrm{I}$ distances (2.49-3.13 $\left.\mathrm{A}, R_{\mathrm{SI}} 0.66-0.83\right)$ and elongated I-I distances (2.75$3.15 \AA$, compared with $2.70 \AA$ in molecular iodine). ${ }^{33,34}$ The S $\cdots$ I and I-I distances are inversely correlated (Fig. 5), indicating a significant charge transfer component to these interactions. Laurence has suggested that the degree to which a base can transfer electrons into the I-I $\sigma^{*}$ orbital is responsible for the extent of elongation of the I-I bond and has reported a correlation between the change in diiodine bond length in the solid state and solution-phase binding constants. $^{34}$ 


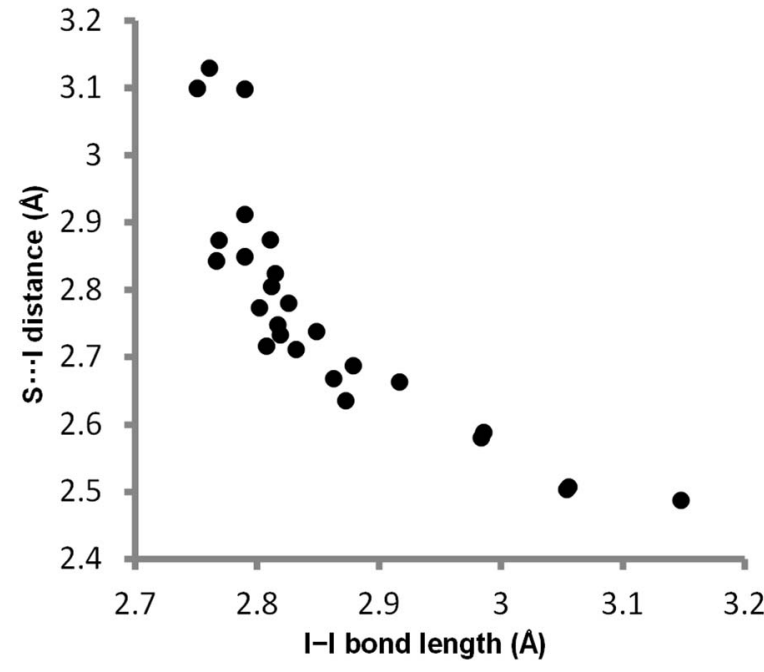

Fig. 5 Plot of $S$...। distance versus $|-|$ bond length in iodine-thiocarbonyl complexes in the Cambridge Structural Database (see Table S3 for details + ).

\section{Conclusions}

The X-bond formed between tetramethylthiourea (4) and molecular iodine (2) is stable in a wide range of different solvents. In contrast to $\mathrm{H}$-bonds, which are very sensitive to solvent polarity, this X-bond is not disrupted even by polar alcohol solvents. The H-bonds formed by 4 to (4-phenylazo) phenol 1 and the X-bonds formed by molecular iodine to tetramethylurea 3 exhibited the expected sensitivity to solvent. These results indicate that the thermodynamic properties of $\mathrm{X}$ bonds cannot be explained by simple electrostatic arguments or the solvent competition model in Fig. 1. We conclude that charge transfer interactions make a significant contribution to the stability of the $\mathbf{2} \cdot \mathbf{4}$ complex and that these interactions are remarkably insensitive to the nature of the solvent.

The X-bonds formed by molecular iodine are significantly stronger than X-bonds formed by organic iodine compounds. ${ }^{23,24}$ However, if the unusual stability the $\mathbf{2} \cdot \mathbf{4}$ complex in polar solvents were a general feature of X-bonded complexes, it should be possible to find combinations of organic X-bond donor and acceptor that show high affinities in polar solvents. Indeed, thermodynamic studies of X-bonded complexes involving organic iodine compounds suggest that stability is not dictated by simple electrostatic considerations. ${ }^{23 a, 35-37}$ Such effects have implications for the application of these non-covalent interactions in water and may provide the opportunity to exploit X-bonding in drug design.

\section{Acknowledgements}

The EPSRC (grants EP/J012998/1 and EP/J012955/1) provided support for this work.

\section{Notes and references}

1 For a provisional IUPAC definition, under review, see http:// www.iupac.org/home/publications/provisional-recommen- dations/published/published-container/definition-of-thehalogen-bond.html.

2 P. Metrangolo, H. Neukirch, T. Pilati and G. Resnati, Acc. Chem. Res., 2005, 38, 386.

3 A. C. Legon, Phys. Chem. Chem. Phys., 2010, 12, 7736.

4 F. Guthrie, J. Chem. Soc., 1863, 16, 239.

5 L. Brammer, G. Mínguez Espallargas and S. Libri, CrystEngComm, 2008, 10, 1712.

6 K. Rissanen, CrystEngComm, 2008, 10, 1107.

7 (a) G. Mínguez Espallargas, L. Brammer and P. Sherwood, Angew. Chem., Int. Ed., 2006, 45, 435; (b) G. Mínguez Espallargas, F. Zordan, L. Arroyo Marín, H. Adams, K. Shankland, J. van de Streek and L. Brammer, Chem.-Eur. J., 2009, 15, 7554.

8 (a) C. B. Aakeröy, M. Fasulo, N. Schultheiss, J. Desper and C. Moore, J. Am. Chem. Soc., 2007, 129, 13772; (b) C. B. Aakeröy, M. Baldrighi, J. Desper, P. Metrangolo and G. Resnati, Chem.-Eur. J., 2013, 19, 16240-16247.

9 (a) J.-Y. Questel, C. Laurence and J. Graton, CrystEngComm, 2013, 15, 3212; (b) C. Perkins, S. Libri, H. Adams and L. Brammer, CrystEngComm, 2012, 14, 3033.

10 A. W. Sun, J. W. Lauher and N. S. Goroff, Science, 2006, 312, 1030.

11 (a) P. Auffinger, F. A. Hays, E. Westhof and P. S. Ho, Proc. Nat. Acad. Sci., 2004, 101, 16789; (b) E. Parisini, P. Metrangolo, T. Pilati, G. Resnati and G. Terraneo, Chem. Soc. Rev., 2011, 40, 2267.

12 (a) Y. Lu, T. Shi, Y. Wang, H. Yang, X. Yan, X. Luo, H. Jiang and W. Zhu, J. Med. Chem., 2009, 52, 2854; (b) R. Wilcken, X. Liu, M. O. Zimmermann, T. J. Rutherford, A. R. Fersht, A. C. Joerger and F. M. Boeckler, J. Am. Chem. Soc., 2012, 134, 6810.

13 (a) S. M. Walter, F. Kniep, E. Herdtweck and S. M. Huber, Angew. Chem., Int. Ed., 2011, 50, 7187; (b) F. Kniep, S. H. Jungbauer, Q. Zhang, S. M. Walter, S. Schindler, I. Schnapperelle, E. Herdtweck and S. M. Huber, Angew. Chem., Int. Ed., 2013, 52, 7028.

14 (a) N. L. Kilah, M. D. Wise, C. J. Serpell, A. L. Thompson, N. G. White, K. E. Christensen and P. D. Beer, J. Am. Chem. Soc., 2010, 132, 11893; (b) C. L. Gilday, T. Lang, A. Caballero, P. J. Costa, V. Felix and P. D. Beer, Angew. Chem., Int. Ed., 2013, 52, 4356.

15 A. V. Jentzsch, A. Henning, J. Mareda and S. Matile, Acc. Chem. Res., 2013, 46, 2791.

16 S. M. Walter, F. Kneip, L. Rout, F. P. Schmidtchen, E. Herdtweck and S. M. Huber, J. Am. Chem. Soc., 2012, 134, 8507.

17 (a) M. Fourmigué and P. Batail, Chem. Rev., 2004, 104, 5379; (b) H. M. Yamamoto, Y. Kosaka, R. Maeda, J. Yamaura, A. Nakao, T. Nakamura and R. Kato, ACS Nano, 2008, 2, 143.

18 T. Shirman, T. Arad and M. E. van der Boom, Angew. Chem., Int. Ed., 2010, 49, 926.

19 L. Meazza, J. A. Foster, K. Fucke, P. Metrangolo, G. Resnati and J. W. Steed, Nat. Chem., 2012, 5, 42.

20 D. W. Bruce, P. Metrangolo, F. Meyer, T. Pilati, C. Präsang, G. Resnati, G. Terraneo, S. G. Wainwright and A. C. Whitwood, Chem.-Eur. J., 2010, 16, 9511. 
21 (a) T. Clark, M. Hennemann, J. Murray and P. Politzer, J. Mol. Model., 2007, 13, 291; (b) F. Zordan, L. Brammer and P. Sherwood, J. Am. Chem. Soc., 2005, 127, 5979.

22 (a) C. Laurence, J. Graton, M. Berthelot and M. El Ghomari, Chem.-Eur. J., 2011, 17, 10431; (b) W. J. McKinney and A. I. Popov, J. Am. Chem. Soc., 1969, 91, 5215.

23 (a) R. Cabot and C. A. Hunter, Chem. Commun., 2009, 15, 2005; (b) T. M. Beale, M. G. Chudzinski, M. G. Sarwar and M. S. Taylor, Chem. Soc. Rev., 2013, 42, 1667.

24 (a) T. Beweries, L. Brammer, N. A. Jasim, J. E. McGrady, R. N. Perutz and A. C. Whitwood, J. Am. Chem. Soc., 2011, 133, 14338; (b) D. A. Smith, L. Brammer, C. A. Hunter and R. N. Perutz, J. Am. Chem. Soc., 2014, 136, 1288.

25 C. Laurence and J. F. Gal, Lewis Basicity and Affinity Scales, John Wiley \& Sons, 2010, pp. 111-227.

26 C. A. Hunter, Angew. Chem., Int. Ed., 2004, 43, 5310.

27 C. S. Calero, J. Farwer, E. J. Gardiner, C. A. Hunter, M. Mackey, S. Scuderi, S. Thompson and J. G. Vinter, Phys. Chem. Chem. Phys., 2013, 15, 18262.

28 J. L. Cook, C. A. Hunter, C. M. R. Low, A. Perez-Velasco and J. G. Vinter, Angew. Chem., Int. Ed., 2007, 46, 3706.

29 M. C. Aragoni, M. Arca, F. A. Devillanova, A. Garau, F. Isaia, V. Lippolis and G. Verani, Coord. Chem. Rev., 1999, 184, 271.

30 (a) R. P. Lang, J. Am. Chem. Soc., 1962, 84, 1185; (b) C. C. Thompson and P. A. D. De Maine, J. Am. Chem. Soc., 1963, 85, 3096; (c) K. R. Bhaskar, R. K. Gosavi and C. N. R. Rao, Trans. Faraday Soc., 1966, 62, 29; (d)
A. Rogstad and E. Augdahl, Acta Chem. Scand., 1971, 25, 225; (e) A.-G. El-Kourashy, Spectrochim.Acta, Part A, 1981, 6, 339; (f) A. Suszka, J. Chem. Soc., Perkin Trans. 2, 1985, 531; $(g)$ F. Bigoli, P. Deplano, M. L. Mercuri, M. A. Pellinghelli, A. Sabatini, E. F. Trogu and A. Vacca, J. Chem. Soc., Dalton Trans., 1996, 3583; (h) P. Deplano, J. R. Ferraro, M. L. Mercuri and E. F. Trogu, Coord. Chem. Rev., 1999, 188, 71.

31 R. A. Binstead, A. D. Zuberbühler and B. Jung, SpecFit/32 (V3.0.34), Spectrum Software Associates, 2003.

32 F. Bigoli, P. Deplano, A. Ienco, C. Mealli, M. L. Mercuri, M. A. Pellinghelli, G. Pintus, G. Saba and E. F. Trogu, Inorg. Chem., 1999, 38, 4626.

33 (a) See $\mathrm{ESI} \dagger$ for list of crystal structures. $R_{\mathrm{SI}}=d(\mathrm{~S} \cdots \mathrm{I}) /\left(r_{\mathrm{S}}+r_{\mathrm{I}}\right)$, where $r_{\mathrm{S}}$ and $r_{\mathrm{I}}$ are the van der Waals radii ${ }^{33 b}$ of sulfur and iodine, following the definition of Lommerse et $a l{ }^{33 c}$; (b) A. Bondi, J. Phys. Chem., 1964, 68, 441; (c) J. P. M. Lommerse, A. J. Stone, R. Taylor and F. H. Allen, J. Am. Chem. Soc., 1996, 118, 3108.

34 C. Ouvrard, J.-Y. Le Questel, M. Berthelot and C. Laurence, Acta Crystallogr., Sect. B: Struct. Sci., 2003, B59, 512.

35 M. G. Chudzinski and M. S. Taylor, J. Org. Chem., 2012, 77, 3483.

36 M. G. Sarwar, B. Dragisic, L. J. Salsberg, C. Gouliaras and M. S. Taylor, J. Am. Chem. Soc., 2010, 132, 1646.

37 L. J. McAllister, D. W. Bruce and P. B. Karadakov, J. Phys. Chem. A, 2012, 116, 10621. 